\title{
Detection and removal of pacing artifacts prior to automated analysis of 12-lead ECG
}

Kazi T. Haq ${ }^{1}$, Ph.D., Neeraj Javadekar ${ }^{1}$, and Larisa G. Tereshchenko' ${ }^{1}$, M.D., Ph.D., FHRS, CCDS.

From

${ }^{1}$ Oregon Health \& Science University, Knight Cardiovascular Institute, Portland, OR.

Correspondence: Larisa Tereshchenko, 3181 SW Sam Jackson Park Rd; UHN62; Portland, OR, 97239. E-mail:tereshch@ohsu.edu.

\section{Short title: Pacing artifact detection and removal}

Words: 4072 


\begin{abstract}
Background: Pacing artifacts must be excluded from the analysis of paced ECG waveform. This study aimed to develop and validate an algorithm to identify and remove the pacing artifacts on ECG.

Methods: We developed a semi-automatic algorithm that identifies the onset and offset of a pacing artifact based on the ECG signal' slope steepness and designed a graphical user interface that permits quality control and fine-tuning the constraining threshold values. We used 1,054 ECGs from the retrospective, multicenter cohort study "Global Electrical Heterogeneity and Clinical Outcomes," including 3,825 atrial and 10,031 ventricular pacing artifacts for the algorithm development and 22 ECGs including 108 atrial and 241 ventricular pacing artifacts for validation. Validation was performed per digital sample. We used the kappa-statistic of interrater agreement between manually labeled sample (ground-truth) and automated detection.

Results: The constraining parameter values were for onset threshold $13.06 \pm 6.21 \mu \mathrm{V} / \mathrm{ms}$, offset threshold $34.77 \pm 17.80 \mu \mathrm{V} / \mathrm{ms}$, and maximum window size $27.23 \pm 3.53 \mathrm{~ms}$. The automated algorithm detected a digital sample belonging to pacing artifact with a sensitivity of $74.5 \%$ and specificity of $99.6 \%$ and classified correctly $98.8 \%$ of digital samples (ROC AUC 0.871; 95\%CI 0.853-0.878). The kappa-statistic was 0.785 , indicating substantial agreement. The agreement was on $98.81 \%$ digital samples, significantly $(P<0.00001)$ larger than the random agreement on $94.43 \%$ of digital samples.
\end{abstract}

Conclusions: The semi-automated algorithm can detect and remove ECG pacing artifacts with high accuracy and provide a user-friendly interface for quality control.

Keywords: pacemaker, pacing artifact, ECG, signal processing 
medRxiv preprint doi: https://doi.org/10.1101/2021.01.21.21250278; this version posted January 22, 2021. The copyright holder for this preprint

(which was not certified by peer review) is the author/funder, who has granted medRxiv a license to display the preprint in perpetuity.

All rights reserved. No reuse allowed without permission.

\section{Highlights}

- We developed and validated a semi-automated algorithm to detect and remove pacing spike artifacts from a digital ECG signal.

- The semi-automated algorithm can detect and remove pacing spike artifacts with high accuracy and provide a user-friendly interface for quality control. 
medRxiv preprint doi: https://doi.org/10.1101/2021.01.21.21250278; this version posted January 22, 2021. The copyright holder for this preprint (which was not certified by peer review) is the author/funder, who has granted medRxiv a license to display the preprint in perpetuity.

All rights reserved. No reuse allowed without permission.

\section{Introduction}

Since the 1950s, cardiac pacing became a vital treatment modality for a growing number of cardiovascular patients. Innovations in cardiac pacing expanded indications for implantable devices capable of delivering cardiac pacing.[1] Pacemaker implantation rates increased from 467 per million in 1993 to 616 per million in 2009.[2] In 2014, an estimated 351,000 pacemaker inpatient procedures were performed in the US.[2] The number of patients living with an implanted cardiac pacemaker is steadily growing.

An electrocardiogram (ECG) is widely used to determine the heart rhythm and to evaluate the performance of pacemaker functioning, especially in emergency settings.[3] Atrial-paced and ventricular-paced rhythm and atrioventricular (AV) dual-paced rhythm are included in the list of core primary ECG diagnostic statements, endorsed by the American Heart Association (AHA), the American College of Cardiology (ACC), the Heart Rhythm Society (HRS), and the International Society for Computerized Electrocardiography (ISCE).[4]

Notably, the ECG diagnostic standards enforced the rule that no secondary statements can accompany the primary diagnostic statement of paced rhythm or paced complexes. [4] The rule[4] stemmed from the dogma about secondary repolarization abnormalities, stating that paced ventricular complexes are examples of secondary repolarization abnormalities.[5] Therefore, the consensus is that paced ECG could only be used to diagnose paced rhythm, but, otherwise, it cannot be clinically useful.[5]

Nevertheless, we,[6] and others, showed that cardiac memory could be detected during continued altered activation.[7] Cardiac memory is neither pure primary nor pure secondary repolarization abnormality.[8, 9] Spatial ventricular gradient (SVG) is independent of the activation sequence.[6, 10, 11] Measurement of SVG on paced ECG furnished clinically useful 
medRxiv preprint doi: https://doi.org/10.1101/2021.01.21.21250278; this version posted January 22, 2021. The copyright holder for this preprint (which was not certified by peer review) is the author/funder, who has granted medRxiv a license to display the preprint in perpetuity.

All rights reserved. No reuse allowed without permission.

information. $[12,13]$ Thus, paced ECG carries important data for meaningful analysis, which needs to be further studied.

The first step in the automated analysis of paced ECG is the removal of pacing artifacts. No such algorithm has been previously developed that can both detect and remove a pacing spike artifact from the 12-lead and orthogonal XYZ ECG. This paper presents the development and validation of a novel semi-automated algorithm to detect and remove pacing artifacts. We tested the hypothesis that the newly developed semi-automated algorithm can accurately detect and remove pacing artifacts from a vectorcardiogram (VCG) obtained from 12-lead ECG.

\section{Methods}

\section{Study population}

We analyzed data from the retrospective, multicenter cohort study "Global Electrical Heterogeneity and Clinical Outcomes" (GEHCO).[13, 14] The study was approved by the Institutional Review Boards at the Oregon Health \& Science University and each participating institution. The study collected digital 12-lead ECG signal recorded before implantation of implantable cardioverter-defibrillator (ICD) or cardiac resynchronization therapy defibrillator (CRT-D). The present study included only patients with atrial-paced (AP), ventricular(including bi-ventricular-) paced (VP), and AV dual- (including atrial and bi-ventricular) paced (AVP) rhythm on available digital 12-lead ECG. Only one (pre-implant) ECG per patient was included in this study.

\section{Algorithm description}

The algorithm and open-source software code written in MATLAB (MathWorks, Natick, MA, USA) are provided at https://github.com/Tereshchenkolab/Pacing_spike_removal. The 
algorithm was developed using 10 -second digital ECG signal with sampling rate $500 \mathrm{~Hz}$. The amplitude resolution was either $1 \mu \mathrm{V}$ or $5 \mu \mathrm{V}$.

Figure 1 shows the flowchart of the developed algorithm. First, baseline wander was removed from the 12-lead ECG. Then XYZ orthogonal ECG was obtained from a 12-lead ECG signal by using the Kors transformation matrix.[15] Once the XYZ leads were obtained, the vector magnitude was calculated from Eq.1.

$$
\|\vec{v}\|=\sqrt{x^{2}+y^{2}+z^{2}}
$$

where $\|\vec{v}\|$ is the vector norm, and $\mathrm{x}, \mathrm{y}$, and $\mathrm{z}$ are the $\mathrm{XYZ}$ orthogonal vectors.

\section{Step 1. Pacing artifact onset detection}

Slope $\left(\frac{d v}{d t}\right)$ was calculated for each pair of the consecutive samples on the 10 -second ECG recording. The algorithm automatically selected the pacing artifact's onset $\left(P_{l}\right)$ if the following condition was satisfied.

$$
\frac{d v}{d t}>\propto_{o n}
$$

where $\alpha_{\mathrm{on}}=$ pacing artifact onset threshold.

\section{Step 2. Pacing artifact offset detection}

Next, the algorithm searched for the pacing artifact's offset. Since the vector norm is an absolute number, the sum of the slopes measured for each pair of the consecutive samples within the pacing artifact tends to zero, assuming that the pacing artifact's offset approaches the baseline, which has a value close to zero. However, in practice, the pacing artifact's offset has a non-zero value due to the saturation effect and baseline deviation. Therefore, we assumed that the offset was an arbitrary positive value, which we referred to as pacing artifact offset threshold,

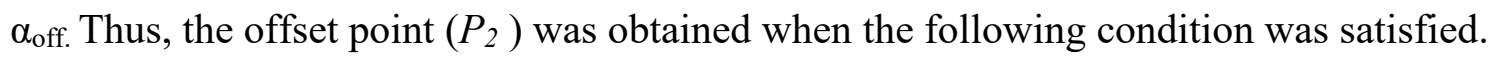




$$
\sum_{i=t_{n}}^{p}\left(\frac{d v}{d t}\right)_{i}<\alpha_{o f f}
$$

where $p=t_{n}+t_{n+1} \ldots \ldots \ldots \ldots \ldots .+t_{p}$ and $\alpha_{\text {off }}=$ pacing artifact's offset threshold.

\section{Step 3. Pacing artifact removal}

Once the onset $\left(P_{1}\right)$ and offset $\left(P_{2}\right)$ time points of a pacing artifact were determined, the spike was removed by making the signal values within the detected pacing artifact time window $\left(P_{1}-\right.$ $P_{2}$ ) equal to the value at the adjacent time point just before $P_{1}$. This was given by,

$$
v\left(t_{p 1}, t_{p 1+1}, t_{p 1+2} \ldots, t_{p 2}\right)=v\left(t_{p 1-1}\right)
$$

where $v=$ signal amplitude.

\section{Graphic user interface}

A graphic user interface was developed that allows users to choose the threshold values from a given range (Figure 2). Additional user-defined parameters were included. Maximum amplitude defines the range of the upper limit value of the signal. Maximum window size defines the range of the sample points considered as the time window of the pacing spike. Re-run allows re-run of the algorithm recursively if a satisfactory result cannot be obtained by altering the thresholds several times. As shown in Figure 2, the dv/dt curve (orange) is superimposed on the vector magnitude plot, which helps the user check whether the maximum $\mathrm{dv} / \mathrm{dt}$ falls within the QRS complex window.

\section{Validation of the automated pacing artifacts detection}

Considering the broad differences in pacing artifacts morphology and duration (because of differences in ECG recording equipment and implanted device manufacturer), we used 98\% of the data (1,054 ECGs including 1,399 atrial, 7,605 ventricular, and 2,426 AV pacing artifacts) 
medRxiv preprint doi: https://doi.org/10.1101/2021.01.21.21250278; this version posted January 22, 2021. The copyright holder for this preprint (which was not certified by peer review) is the author/funder, who has granted medRxiv a license to display the preprint in perpetuity.

All rights reserved. No reuse allowed without permission.

for the algorithm development and 2\% of the data (22 ECGs including 108 atrial and 241 ventricular pacing artifacts) for validation.

For validation, to obtain the ground truth, one investigator (NJ) manually labeled each sample on digital ECG signal as either belonging to pacing artifact (Yes) or not (No). Another investigator $(\mathrm{KTH})$ ran an automated algorithm and similarly reported each data sample results as pacing artifact Yes or No. The investigators (NJ and KTH) were blinded to each other results. The third investigator (LGT) conducted statistical analysis.

\section{Statistical analysis}

Statistical analysis was performed using STATA MP 16.1 (StataCorp LLC, College Station, TX, USA). Continuous variables were reported as mean \pm standard deviation (SD). We used the kappa-statistic measure of interrater agreement for two independent raters. Nonparametric receiver operating characteristic (ROC) analysis with a rating and discrete classification data was performed to calculate the area under the ROC curve (ROC AUC) and measure the automated pacing artifact detection's sensitivity and specificity.

\section{Results}

\section{Study population}

Clinical and demographic characteristics of the study population are reported in Table 1. This study included heart failure patients, mostly white men. Approximately half of the patients had nonischemic cardiomyopathy, and one-third had diabetes. Most of the patients (70\%) had CRTD implanted, and 30\% had ICD implanted. Implanted devices were manufactured by four companies (Table 1), which allowed us to develop the algorithm that considered various features 
medRxiv preprint doi: https://doi.org/10.1101/2021.01.21.21250278; this version posted January 22, 2021. The copyright holder for this preprint (which was not certified by peer review) is the author/funder, who has granted medRxiv a license to display the preprint in perpetuity.

All rights reserved. No reuse allowed without permission.

of pacing pulses by different manufacturers. The vast majority of patients $(86 \%)$ had a VP or AVP rhythm on analyzed ECG. An average heart rate was 70 beats per minute.

\section{Algorithm development and validation}

For the algorithm development, to determine the $P_{1}$ and $P_{2}$ thresholds, we detected and removed 1,399 atrial, 7,605 ventricular, and 2,426 AV pacing artifacts. Figure 3 shows a representative example of pacing artifacts removal from a VP VCG vector magnitude signal. Figure 4 shows another example where pacing artifacts were removed from an AVP VCG vector magnitude signal.

From the validation dataset ( $n=22$ ECGs) the mean of 4 constraining parameter values were found as : mean maximum amplitude $146.36 \pm 76.36 \mu \mathrm{V}$, mean onset threshold $\left(\alpha_{\mathrm{on}}\right) 13.06 \pm 6.21$ $\mu \mathrm{V} / \mathrm{ms}$, mean offset threshold $\left(\alpha_{\text {off }}\right) 34.77 \pm 17.80 \mu \mathrm{V} / \mathrm{ms}$, and mean maximum window size 27.23 $\pm 3.53 \mathrm{~ms}$.

For validation of the automated algorithm, we analyzed 110,000 digital signal samples. Each ECG had 5000 samples. On average, a pacing artifact occupied $9.2 \pm 3.2$ samples or $18.4 \pm 6.4 \mathrm{~ms}$. Notably, the automated algorithm detected the presence of pacing artifact with $100 \%$ accuracy, $100 \%$ sensitivity, and 100\% specificity.

Two-by-two table (Table 2) reports an agreement between the ground truth and automated detection of pacing artifacts for each sample of the digital ECG data. If the automated algorithm had made the determination randomly (but with probabilities equal to the overall proportions), we would expect the agreement on $94.43 \%$ of digital samples. In fact, they agreed on $98.81 \%$. The amount of agreement indicated that we could reject the null hypothesis that they were making their determination randomly $(P<0.00001)$. The kappa-statistic was 0.785 , indicating substantial agreement. 
medRxiv preprint doi: https://doi.org/10.1101/2021.01.21.21250278; this version posted January 22, 2021. The copyright holder for this preprint (which was not certified by peer review) is the author/funder, who has granted medRxiv a license to display the preprint in perpetuity.

All rights reserved. No reuse allowed without permission.

The automated algorithm assigned a digital sample to pacing artifact with ROC AUC 0.871 (95\% confidence interval $0.853-0.878)$, a sensitivity of $74.5 \%$, and specificity of $99.6 \%$ and classified correctly $98.8 \%$ of digital samples.

\section{Discussion}

In this work, we developed and validated the semi-automated algorithm to detect and remove pacing artifacts from a digital ECG signal. The fully automated algorithm was perfectly $100 \%$ accurate in detection of a pacing artifact's presence, and demonstrated $75 \%$ sensitivity and 100\% specificity for the per-digital-sample automated detection of pacing artifacts, whereas a userfriendly interface allowed additional fine-tuning and quality control of the artifact removal.

Current ECG machines convert the analog ECG signal to digital at the front end.[16] Modern pacemaker's stimulus output is frequently $\leq 0.25 \mathrm{~ms}$ in duration. Therefore, front-end sampling has to be $\geq 10,000$ samples per second in order to detect and represent the pacemaker's stimulus output. Furthermore, contemporary bipolar pacemaker's stimulus output is usually small (2-4 Volt). The AHA/ACC/HRS/ISCE-endorsed recommendations for the standardization and interpretation of the ECG[16] emphasized that ECG manufacturers should maintain the required front-end sampling rate for reliable and accurate detection of narrow pacemaker pulses but should not artificially increase pulses' amplitude to avoid ECG's morphology distortion. However, in clinical settings, the information about the front-end sampling rate and an approach to handling the presentation of pacemaker stimulus outputs by a specific ECG recording machine is not readily available. In a nonselective CRT patient population, cardiologists observed visible ventricular pacing artifacts in $90 \%$ and visible atrial pacing artifacts - in $70 \%$ of patients with paced rhythm, whereas the automated ECG reading algorithm detected only $20 \%$ of patients with VP rhythm, and none with AP rhythm.[17] 
medRxiv preprint doi: https://doi.org/10.1101/2021.01.21.21250278; this version posted January 22, 2021. The copyright holder for this preprint (which was not certified by peer review) is the author/funder, who has granted medRxiv a license to display the preprint in perpetuity.

All rights reserved. No reuse allowed without permission.

In accordance with the growing population of patients with implanted pacemakers, ICD, and CRT devices, the list of meaningful interpretations of paced ECG morphology is expanding. Acute myocardial infarction can manifest on ECG in patients with VP rhythm, although the sensitivity of acute myocardial infarction diagnosis on paced ECG is low.[18, 19] Left ventricular paced QRS width and the difference between biventricular-paced and pre-implant QRS width predict CRT response.[20] Our previous study showed that the addition of global electrical heterogeneity (GEH) ECG metrics to clinical risk factors of sudden cardiac death (SCD) is especially rewarding in the presence of paced rhythms.[12] In a subgroup of participants with VP ECG (Supplemental Table 13 in [12]), with the addition of GEH parameters, $33 \%$ of SCD victims were appropriately reclassified into a higher-risk category (from low to high risk). In contrast, only $10 \%$ were similarly appropriately reclassified amongst participants without a paced rhythm on ECG. Furthermore, in the VP rhythm subgroup, no SCD victims were inappropriately reclassified from high to low risk. The addition of GEH also improved SCD-specific risk prediction. The proportion of SCD decreased from $12 \%$ to $6 \%$ in the intermediate-risk group and increased from $15 \%$ to $18 \%$ in the high-risk group. The large prospective study of more than 20,000 participants with a median of 14 years of follow-up showed clinical usefulness of GEH measurements on VP ECG.[12]

Therefore, there is a growing need for reliable detection of pacing artifacts and accurate analysis of paced ECG morphology. Particularly, while the pacing artifact detection is important for the diagnosis of a paced rhythm, the pacing artifact itself should be removed from the analysis of the paced ECG waveform. As discussed above, an ideal solution endorsed by the AHA/ACC/HRS/ISCE involves the oversampling at the ECG front end at $\geq 10,000 \mathrm{~Hz}$, saving pacing artifacts data on a unique marker-channel, and subsequent downsampling to $500-1000 \mathrm{~Hz}$ 
medRxiv preprint doi: https://doi.org/10.1101/2021.01.21.21250278; this version posted January 22, 2021. The copyright holder for this preprint (which was not certified by peer review) is the author/funder, who has granted medRxiv a license to display the preprint in perpetuity.

All rights reserved. No reuse allowed without permission.

for conventional ECG signal analysis and storage.[16] For example, the algorithm described by Polpetta and Banelli[21] follows the recommended approach and reports promising results.

Unfortunately, in clinical settings, it is usually unknown which front-end algorithm is utilized by a given ECG machine manufacturer. If an ECG has been recorded using unknown front-end characteristics, signal processing is the only option. A few previous fully automated algorithms addressed pacing artifacts detection. Helfenbein et al.[22] developed an algorithm for pacing artifacts detection on a commonly used ECG signal (sampling rate 500Hz, bandwidth $0.05-150$ $\mathrm{Hz}$ ), capitalizing on the fact that low-pass filtering broadens the pacing artifact width. The authors reported a sensitivity of $97.2 \%$ for detecting a paced rhythm,[22] which is lower than our results. Notably, the authors did not report an accuracy and algorithm performance per each sample of the digital ECG signal. Furthermore, widely used algorithms[22] are based on filtering the ECG signal, which distorts the beginning of the QRS and widens the QRS complex. The distortion of the QRS complex challenges the clinical use of paced QRS morphology measurements.[20]

Up-to-date, our semi-automated algorithm is the only available solution for careful and accurate pacing artifacts removal, as required for the analysis of QRS morphology. Allowing the user to select the dynamic thresholds from a range of values offers the required flexibility, considering different pacing pulse characteristics produced by a wide range of pacemakers' manufacturers. Moreover, the user can monitor spike removal's effects on the signal and choose an alternative set of thresholds until satisfactory results are achieved.

\section{Limitations}

This paper presented a semi-automated algorithm to detect and remove pacing spikes artifacts from ECG. However, the algorithm itself is not fully automatic. Semi-automated 
medRxiv preprint doi: https://doi.org/10.1101/2021.01.21.21250278; this version posted January 22, 2021. The copyright holder for this preprint (which was not certified by peer review) is the author/funder, who has granted medRxiv a license to display the preprint in perpetuity.

All rights reserved. No reuse allowed without permission.

approach is time-consuming. However, the pacing spikes from diverse patient populations and pacemaker settings always come with a high degree of variability, making automated dynamic threshold estimation challenging, though not impossible. We have to emphasize that the ideal approach for the analysis of paced ECG waveform morphology has to include ECG front-end oversampling[16], recording the presence of pacing artifacts on a separate marker-channel, and immediate its removat at the front end. Removal of a pacing artifact at the front end preserves paced ECG morphology for its subsequent analysis. Growing number of patients with implanted pacemaker devices and clinical needs for a meaningful analysis of paced ECG waveform[12, 13, 20] calls for ECG manufacturers attention to handling ECG front-end manufacturing.

\section{Conclusions}

We developed a semi-automated algorithm to detect and remove pacing spike artifacts from digital ECG signal. The algorithm demonstrated its ability to detect and remove pacing spike artifacts with high sensitivity and specificity.

\section{Funding:}

This work was partially supported by the National Institutes of Health (HL118277), Medical Research Foundation of Oregon and OHSU President Bridge funding to Tereshchenko.

\section{Acknowledgment}

The authors thank all GEHCO investigators. 


\section{References}

[1] A. Cheng, L.G. Tereshchenko, Evolutionary innovations in cardiac pacing, Journal of Electrocardiology, 44 (2011) 611-615.

[2] S.S. Virani, A. Alonso, E.J. Benjamin, M.S. Bittencourt, C.W. Callaway, A.P. Carson, A.M. Chamberlain, A.R. Chang, S. Cheng, F.N. Delling, L. Djousse, M.S.V. Elkind, J.F. Ferguson, M. Fornage, S.S. Khan, B.M. Kissela, K.L. Knutson, T.W. Kwan, D.T. Lackland, T.T. Lewis, J.H. Lichtman, C.T. Longenecker, M.S. Loop, P.L. Lutsey, S.S. Martin, K. Matsushita, A.E. Moran, M.E. Mussolino, A.M. Perak, W.D. Rosamond, G.A. Roth, U.K.A. Sampson, G.M. Satou, E.B. Schroeder, S.H. Shah, C.M. Shay, N.L. Spartano, A. Stokes, D.L. Tirschwell, L.B. VanWagner, C.W. Tsao, American Heart Association Council on Epidemiology, Prevention Statistics Committee, Stroke Statistics Subcommittee, Heart Disease and Stroke Statistics-2020 Update: A Report From the American Heart Association, Circulation, 141 (2020) e139-e596.

[3] S.E. Greenhut, J.M. Jenkins, L.A. Dicarlo, Computerized interpretation of the paced ECG, Journal of Electrocardiology, 24 (1991) 146-152.

[4] J.W. Mason, E.W. Hancock, L.S. Gettes, Recommendations for the standardization and interpretation of the electrocardiogram, Heart Rhythm, 4 (2007) 413-419.

[5] P.M. Rautaharju, B. Surawicz, L.S. Gettes, AHA/ACCF/HRS Recommendations for the Standardization and Interpretation of the Electrocardiogram, Journal of the American College of Cardiology, 53 (2009) 982-991.

[6] K. Haq, J. Cao, L.G. Tereshchenko, Characteristics of Cardiac Memory in Patients with Implanted Cardioverter Defibrillator: the CAMI study, medRxiv, (2019) https://doi.org/10.1101/19005181. 
[7] A. Shvilkin, B. Bojovic, B. Vajdic, I. Gussak, K.K. Ho, P. Zimetbaum, M.E. Josephson, Vectorcardiographic and electrocardiographic criteria to distinguish new and old left bundle branch block, Heart Rhythm., 7 (2010) 1085-1092.

[8] M.B. Rosenbaum, H.H. Blanco, M.V. Elizari, J.O. Lázzari, J.M. Davidenko, Electrotonic modulation of the T wave and cardiac memory, American Journal of Cardiology, 50 (1982) 213222.

[9] N. Ozgen, M.R. Rosen, Cardiac memory: a work in progress, Heart Rhythm., 6 (2009) 564570.

[10] L.G. Tereshchenko, R.N. Ghanem, A. Abeyratne, C.D. Swerdlow, Intracardiac QT integral on far-field ICD electrogram predicts sustained ventricular tachyarrhythmias in ICD patients, Heart Rhythm, 8 (2011) 1889-1894.

[11] H.C. Burger, A theoretical elucidation of the notion ventricular gradient, American Heart Journal, 53 (1957) 240-246.

[12] J.W. Waks, C.M. Sitlani, E.Z. Soliman, M. Kabir, E. Ghafoori, M.L. Biggs, C.A. Henrikson, N. Sotoodehnia, T. Biering-Sorensen, S.K. Agarwal, D.S. Siscovick, W.S. Post, S.D. Solomon, A.E. Buxton, M.E. Josephson, L.G. Tereshchenko, Global Electric Heterogeneity Risk Score for Prediction of Sudden Cardiac Death in the General Population: The Atherosclerosis Risk in Communities (ARIC) and Cardiovascular Health (CHS) Studies, Circulation, 133 (2016) $2222-2234$.

[13] J.W. Waks, K.T. Haq, C. Tompkins, A.J. Rogers, A. Ehdaie, A. Bender, J. Minnier, K. Dalouk, S. Howell, A. Peiris, M. Raitt, S.M. Narayan, S. Chugh, L.G. Tereshchenko, Competing Risks in Patients with Primary Prevention Implantable Cardioverters Defibrillators: Global 
medRxiv preprint doi: https://doi.org/10.1101/2021.01.21.21250278; this version posted January 22, 2021. The copyright holder for this preprint (which was not certified by peer review) is the author/funder, who has granted medRxiv a license to display the preprint in perpetuity.

All rights reserved. No reuse allowed without permission.

Electrical Heterogeneity and Clinical Outcomes (GEHCO) Study, medRxiv, 12 (2020) 20248369.

[14] J.W. Waks, C. Hamilton, S. Das, A. Ehdaie, J. Minnier, S. Narayan, M. Niebauer, M. Raitt, C. Tompkins, N. Varma, S. Chugh, L.G. Tereshchenko, Improving sudden cardiac death risk stratification by evaluating electrocardiographic measures of global electrical heterogeneity and clinical outcomes among patients with implantable cardioverter-defibrillators: rationale and design for a retrospective, multicenter, cohort study, J Interv Card Electrophysiol, 52 (2018) 7789.

[15] J.A. Kors, H.G. van, A.C. Sittig, J.H. van Bemmel, Reconstruction of the Frank vectorcardiogram from standard electrocardiographic leads: diagnostic comparison of different methods, Eur.Heart J, 11 (1990) 1083-1092.

[16] P. Kligfield, L.S. Gettes, J.J. Bailey, R. Childers, B.J. Deal, E.W. Hancock, H.G. van, J.A. Kors, P. Macfarlane, D.M. Mirvis, O. Pahlm, P. Rautaharju, G.S. Wagner, M. Josephson, J.W. Mason, P. Okin, B. Surawicz, H. Wellens, Recommendations for the standardization and interpretation of the electrocardiogram: part I: the electrocardiogram and its technology a scientific statement from the American Heart Association Electrocardiography and Arrhythmias Committee, Council on Clinical Cardiology; the American College of Cardiology Foundation; and the Heart Rhythm Society endorsed by the International Society for Computerized Electrocardiology, J Am Coll.Cardiol., 49 (2007) 1109-1127.

[17] H.B. Andersson, M.B. Hansen, M. Thorsberger, T. Biering-Sørensen, J.B. Nielsen, C. Graff, S. Pehrson, J.H. Svendsen, Diagnostic accuracy of pace spikes in the electrocardiogram to diagnose paced rhythm, Journal of electrocardiology, 48 (2015) 834-839. 
medRxiv preprint doi: https://doi.org/10.1101/2021.01.21.21250278; this version posted January 22, 2021. The copyright holder for this preprint (which was not certified by peer review) is the author/funder, who has granted medRxiv a license to display the preprint in perpetuity.

All rights reserved. No reuse allowed without permission.

[18] E.B. Sgarbossa, S.L. Pinski, K.B. Gates, G.S. Wagner, Early electrocardiographic diagnosis of acute myocardial infarction in the presence of ventricular paced rhythm. GUSTO-I investigators, Am J Cardiol, 77 (1996) 423-424.

[19] W.J. Brady, B. Lentz, K. Barlotta, R.A. Harrigan, T. Chan, ECG Patterns Confounding the ECG Diagnosis of Acute Coronary Syndrome: Left Bundle Branch Block, Right Ventricular Paced Rhythms, and Left Ventricular Hypertrophy, Emergency Medicine Clinics of North America, 23 (2005) 999-1025.

[20] J.M. Hsing, K.A. Selzman, C. Leclercq, L.A. Pires, M.G. McLaughlin, S.E. McRae, B.J. Peterson, P.J. Zimetbaum, Paced left ventricular QRS width and ECG parameters predict outcomes after cardiac resynchronization therapy: PROSPECT-ECG substudy, Circ Arrhythm Electrophysiol, 4 (2011) 851-857.

[21] A. Polpetta, P. Banelli, Fully digital pacemaker detection in ECG signals using a non-linear filtering approach, Annu Int Conf IEEE Eng Med Biol Soc, 2008 (2008) 5406-5410.

[22] E.D. Helfenbein, J.M. Lindauer, S.H. Zhou, R.E. Gregg, E.C. Herleikson, A software-based pacemaker pulse detection and paced rhythm classification algorithm, Journal of Electrocardiology, 35 (2002) 95-103. 


\section{Table 1. Study population characteristics}

\begin{tabular}{|c|c|}
\hline & All patients $(\mathrm{n}=454)$ \\
\hline $\operatorname{Age}($ mean \pm SD $)$, yrs & $67.6 \pm 12.3$ \\
\hline Female, \% & 23.8 \\
\hline White, $\%$ & 81.1 \\
\hline Nonischemic cardiomyopathy, $\%$ & 42.4 \\
\hline Hypertension, \% & 73.1 \\
\hline Diabetes, $\%$ & 33.4 \\
\hline Use class I or III antiarrhythmic drugs, $\%$ & 16.7 \\
\hline Use beta-blockers, $\%$ & 84.5 \\
\hline Left ventricular ejection fraction(mean \pm SD), $\%$ & $29.3 \pm 12.2$ \\
\hline New York Heart Association heart failure class I-II, \% & 49.3 \\
\hline New York Heart Association heart failure class III-IV, \% & 50.7 \\
\hline Single-chamber implantable cardioverter-defibrillator, \% & 7.5 \\
\hline Dual-chamber implantable cardioverter-defibrillator, \% & 22.8 \\
\hline Cardiac resynchronization therapy defibrillator, \% & 69.7 \\
\hline Decice manufacturer Medtronic, $\%$ & 67.7 \\
\hline Decice manufacturer Guidant/Boston Scientific, \% & 17.5 \\
\hline Decice manufacturer St. Jude/Abbott, \% & 13.5 \\
\hline Device manufacturer Biotronic, $\%$ & 1.3 \\
\hline Atrial-paced rhythm, n(\%) & $62(13.7)$ \\
\hline Ventricular-paced rhythm, n(\%) & $282(62.1)$ \\
\hline Atrio-ventricular paced rhythm, $\mathrm{n}(\%)$ & $110(24.2)$ \\
\hline Heart rate $($ mean $\pm S D)$, beats per minute & $70.1 \pm 12.3$ \\
\hline QRS duration (mean \pm SD), ms & $130.7 \pm 35.3$ \\
\hline Bazett-corrected QT interval (mean \pm SD), ms & $484.0 \pm 51.3$ \\
\hline
\end{tabular}


medRxiv preprint doi: https://doi.org/10.1101/2021.01.21.21250278; this version posted January 22, 2021. The copyright holder for this preprint

(which was not certified by peer review) is the author/funder, who has granted medRxiv a license to display the preprint in perpetuity.

All rights reserved. No reuse allowed without permission.

Table 2. Two by two table of a per-sample agreement between the ground trith and automated algorithm detection of pacing artifacts

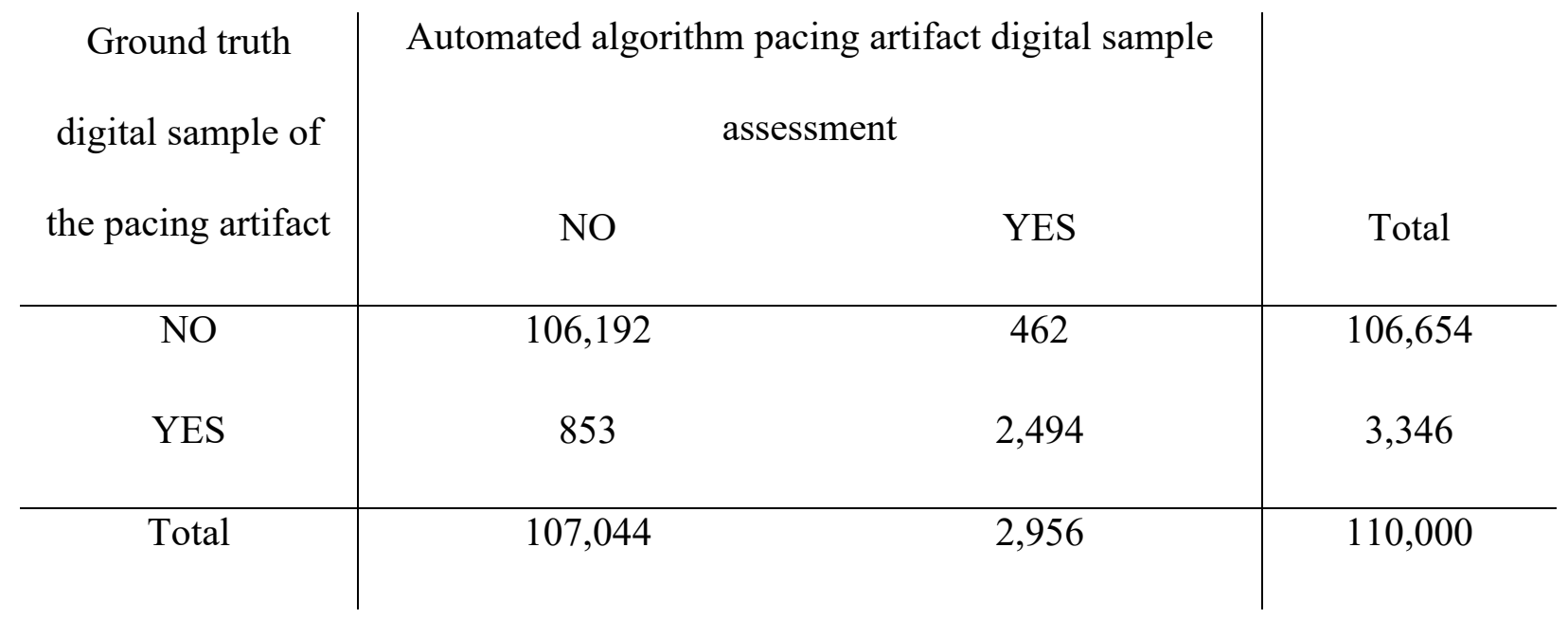


medRxiv preprint doi: https://doi.org/10.1101/2021.01.21.21250278; this version posted January 22, 2021. The copyright holder for this preprint

(which was not certified by peer review) is the author/funder, who has granted medRxiv a license to display the preprint in perpetuity.

All rights reserved. No reuse allowed without permission.

\section{Figure Legends}

Figure 1. A. Flowchart representation of the algorithm to detect and remove a pacing artifact. B. Representative example of a pacing artifact on vector magnitude ECG signal.

Figure 2. Graphic user interface for pacing artifact removal. The interface allows users to input threshold parameters and review the output for each set of chosen parameters.

Figure 3. Example of pacing artifact removal from a ventricular-paced VCG. A) Original ventricular-paced VCG vector magnitude signal. B) Detected pacing artifacts (blue) and VCG signal (red). C) VCG vector magnitude signal after removal of pacing artifacts. The pacing spike onset $\left(\alpha_{o n}\right)$ and offset $\left(\alpha_{o f f}\right)$ threshold values were 5 and $10 \mu \mathrm{V} / \mathrm{ms}$, respectively.

Figure 4. Example of pacing spike removal from AV-paced VCG. A) Original AV-paced VCG vector magnitude signal. B) Detected pacing artifacts (blue) and VCG signal (red). C) VCG vector magnitude signal after removal of pacing artifacts. The corresponding value of $\alpha_{\text {on }}$ and $\alpha_{\text {off }}$ were 7.5 and $15.5 \mu \mathrm{V} / \mathrm{ms}$, respectively.

Figure 5. Example of pacing artifacts removal from 12-lead ECG a) 12-lead ECG with pacing artifacts. b) 12-lead ECG trace after pacing artifacts removal. 
medRxiv preprint doi: https://doi.org/10.1101/2021.01.21.21250278; this version posted January 22, 2021. The copyright holder for this preprint (which was not certified by peer review) is the author/funder, who has granted medRxiv a license to display the preprint in perpetuity.

All rights reserved. No reuse allowed without permission.

\section{Figure 1:}

a)

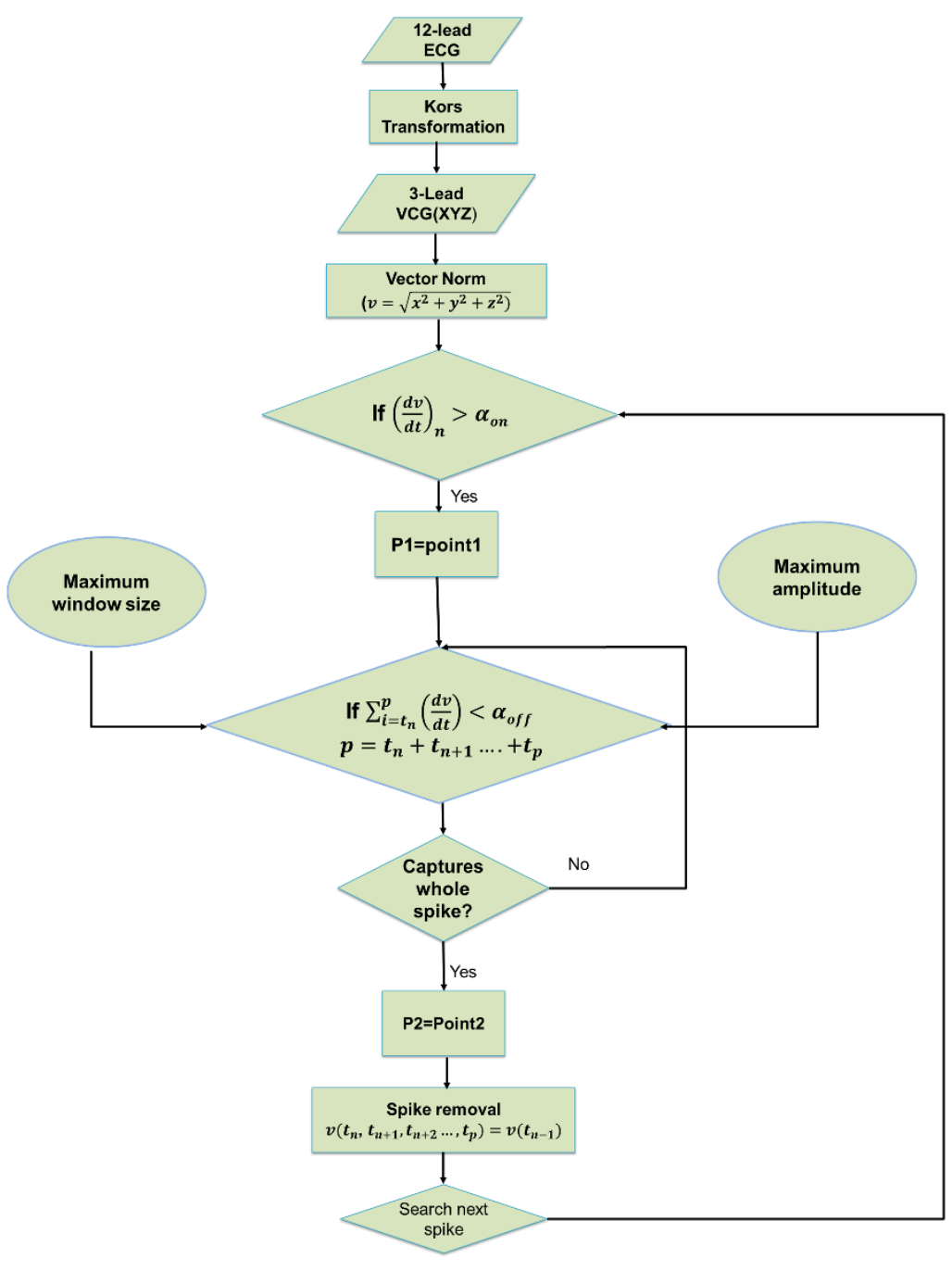

b)

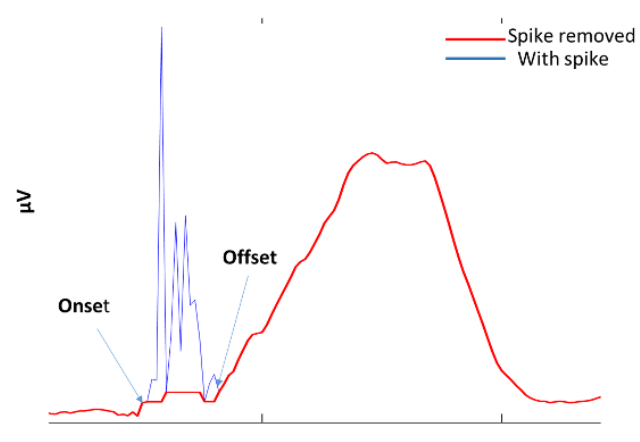

ms 
Figure 2:

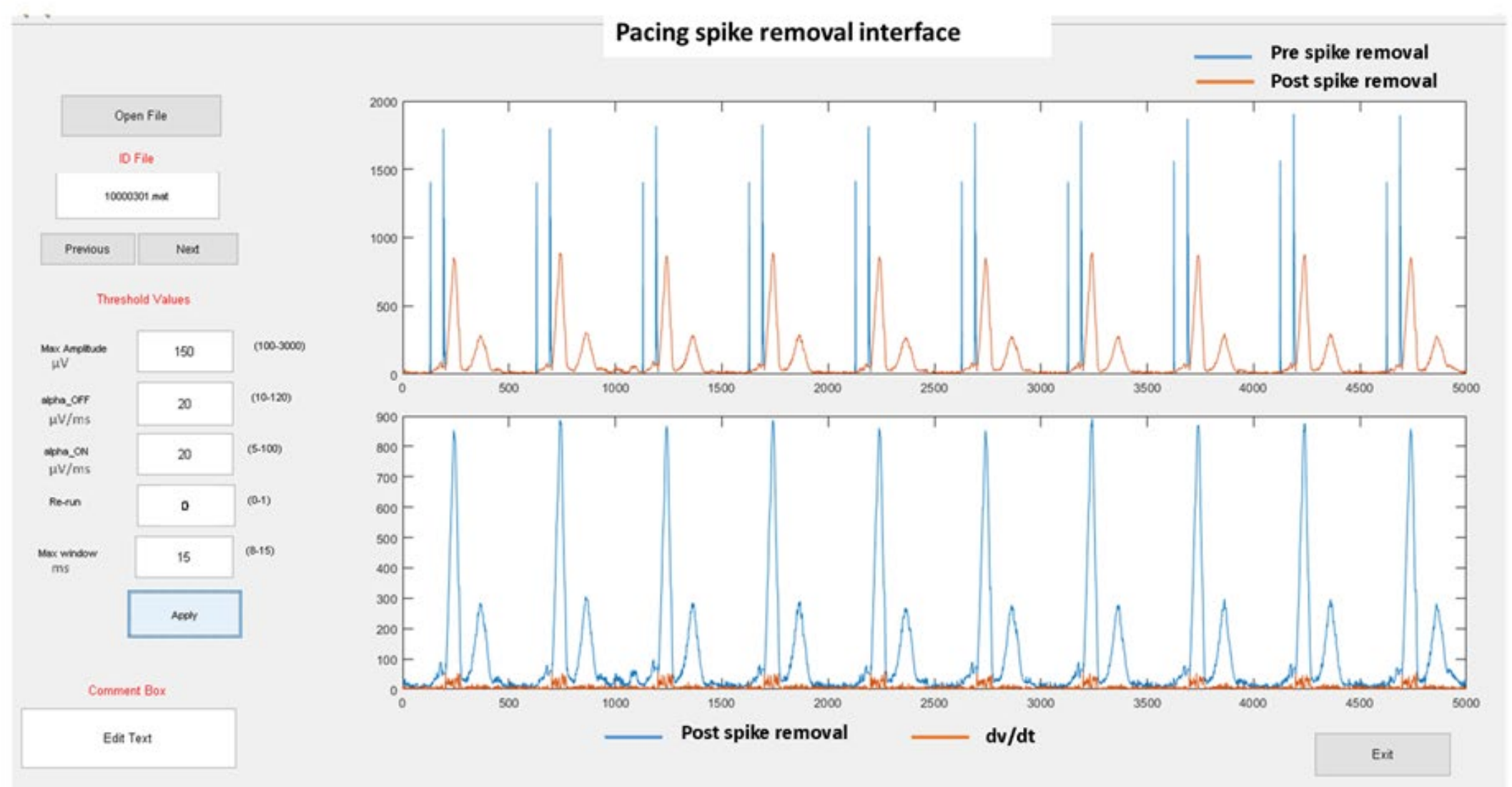


Figure 3:

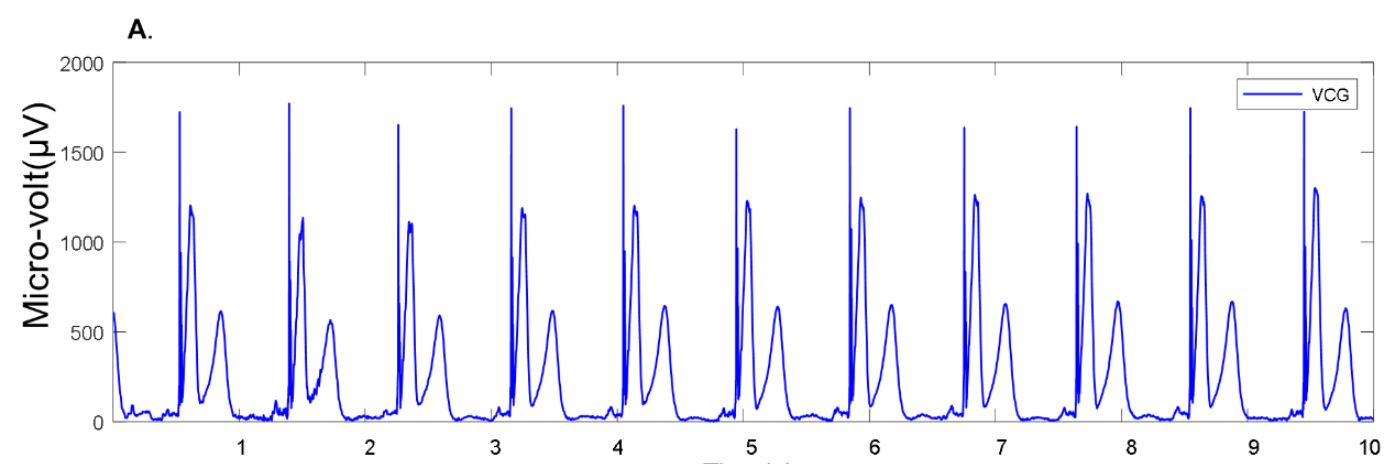

B.
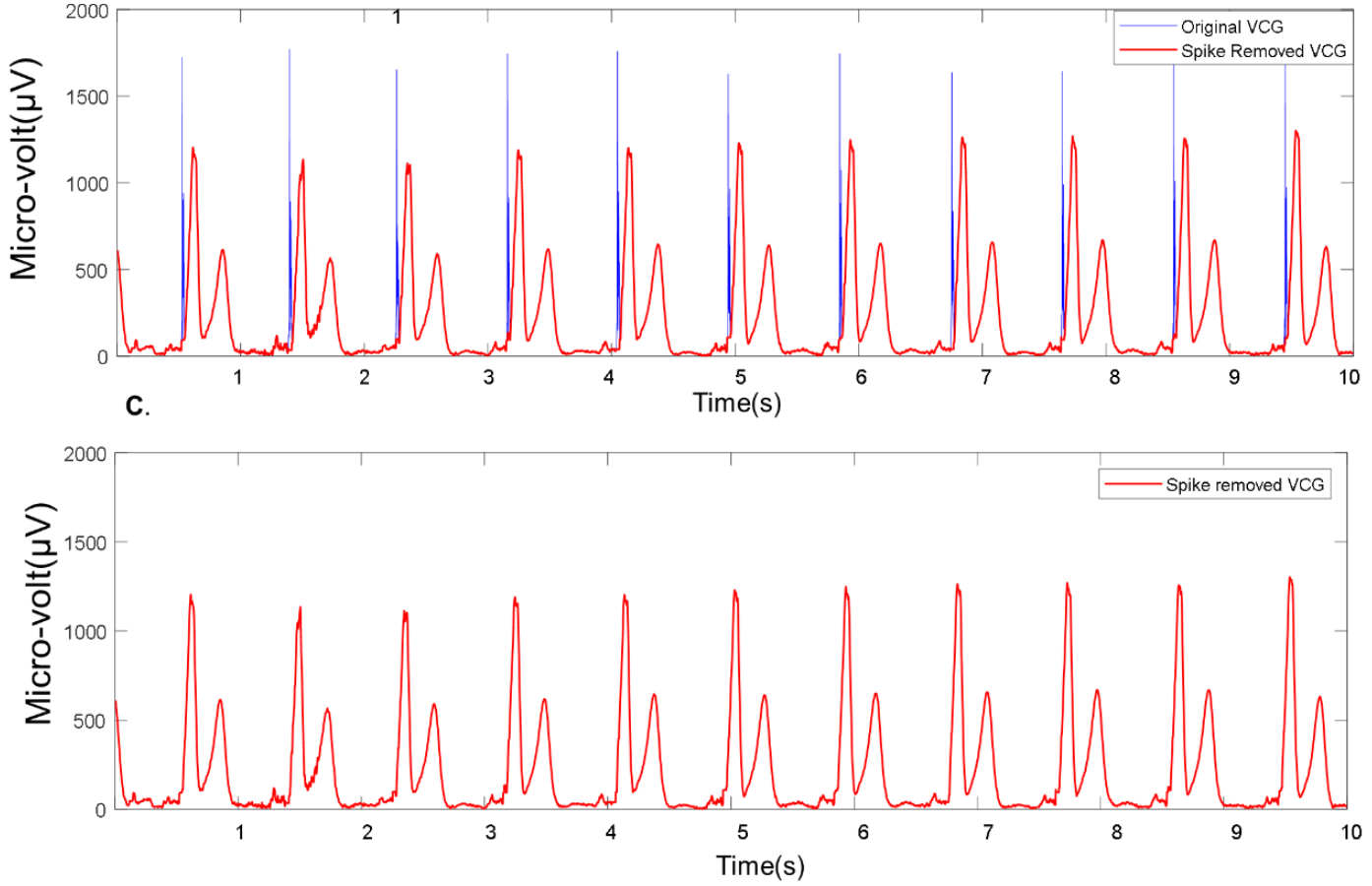
medRxiv preprint doi: https://doi.org/10.1101/2021.01.21.21250278; this version posted January 22, 2021. The copyright holder for this preprint (which was not certified by peer review) is the author/funder, who has granted medRxiv a license to display the preprint in perpetuity. All rights reserved. No reuse allowed without permission.

\section{Figure 4:}

A.

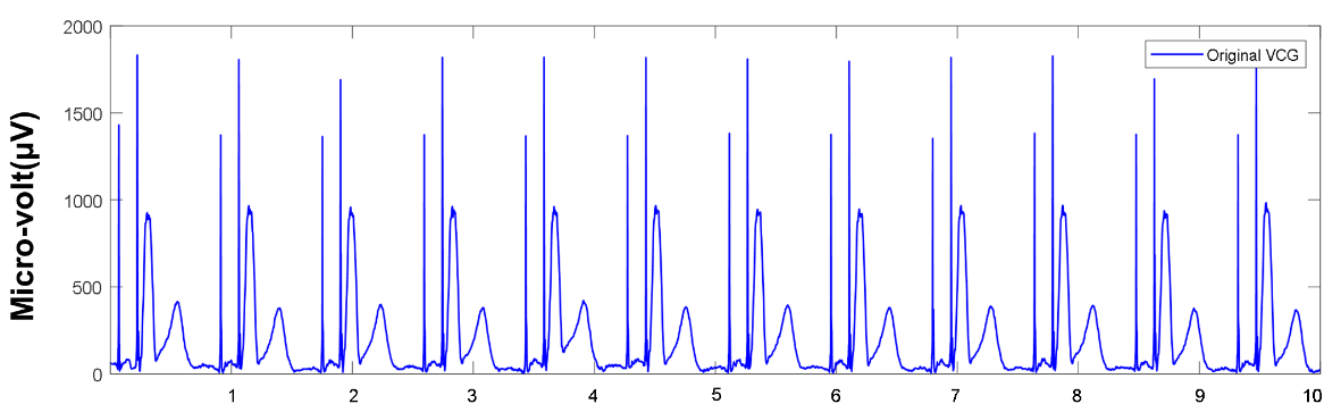

B.

Time(s)

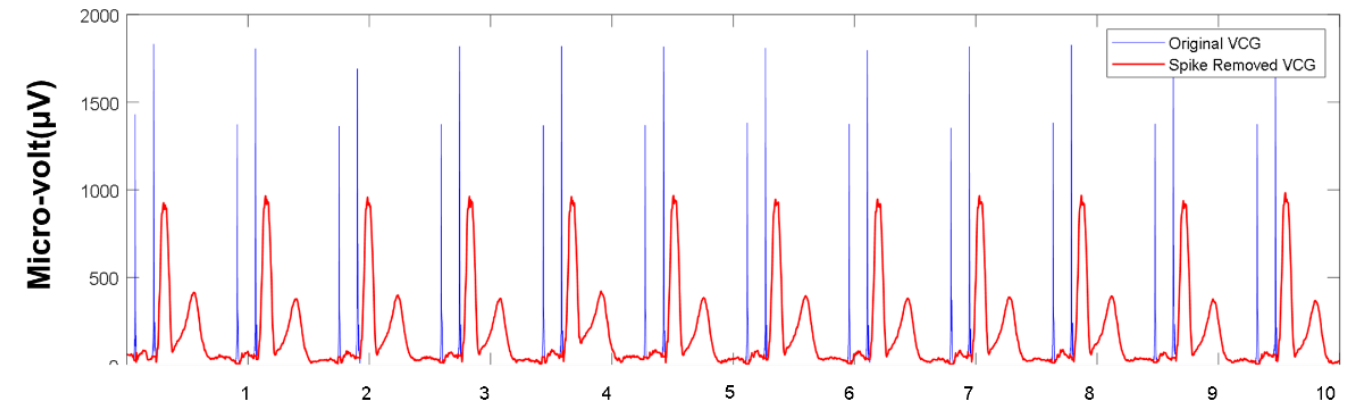

c.

Time(s)

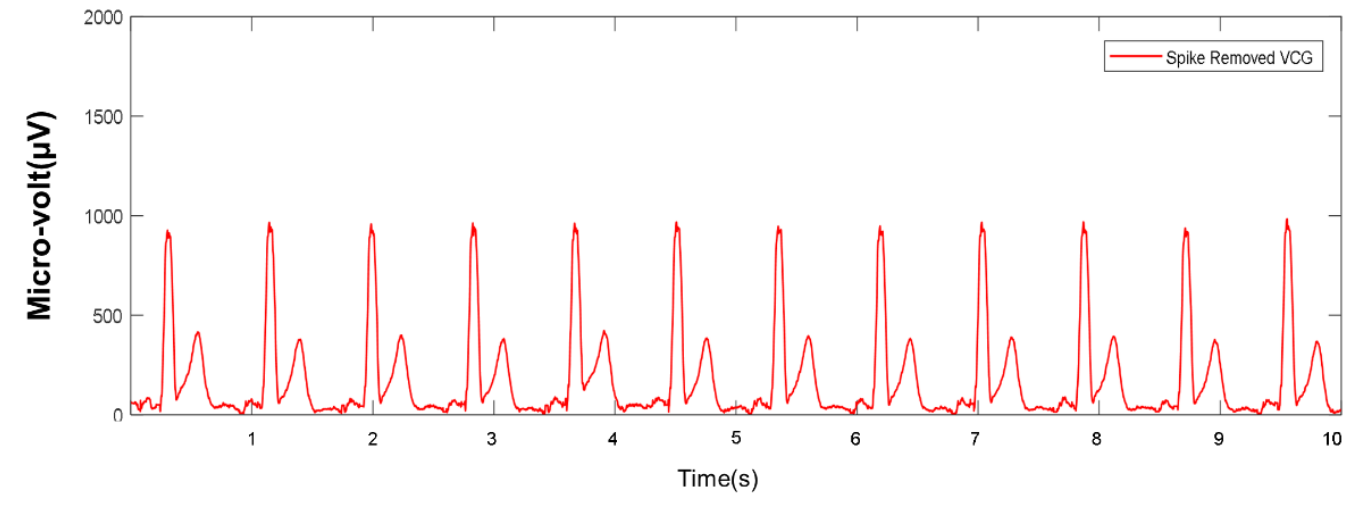




\section{Figure 5:}

a)
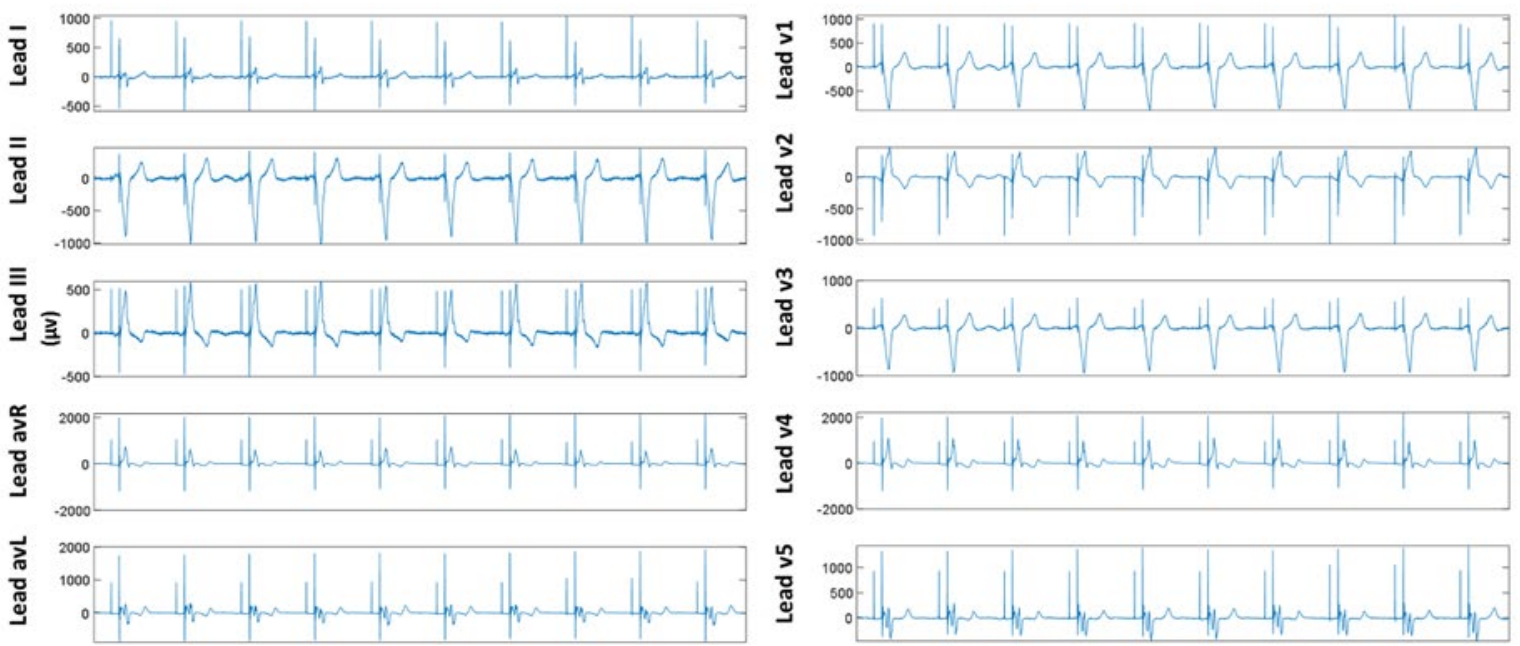

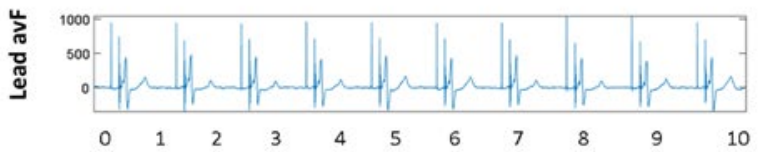

(s)

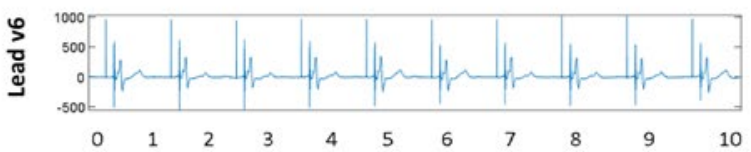

(s)

b)

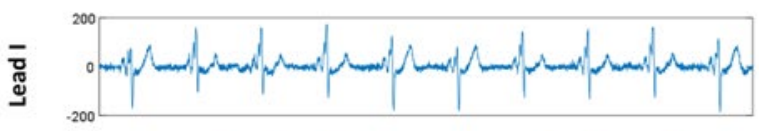

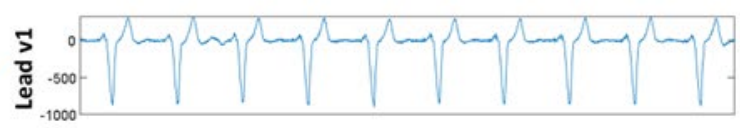

=
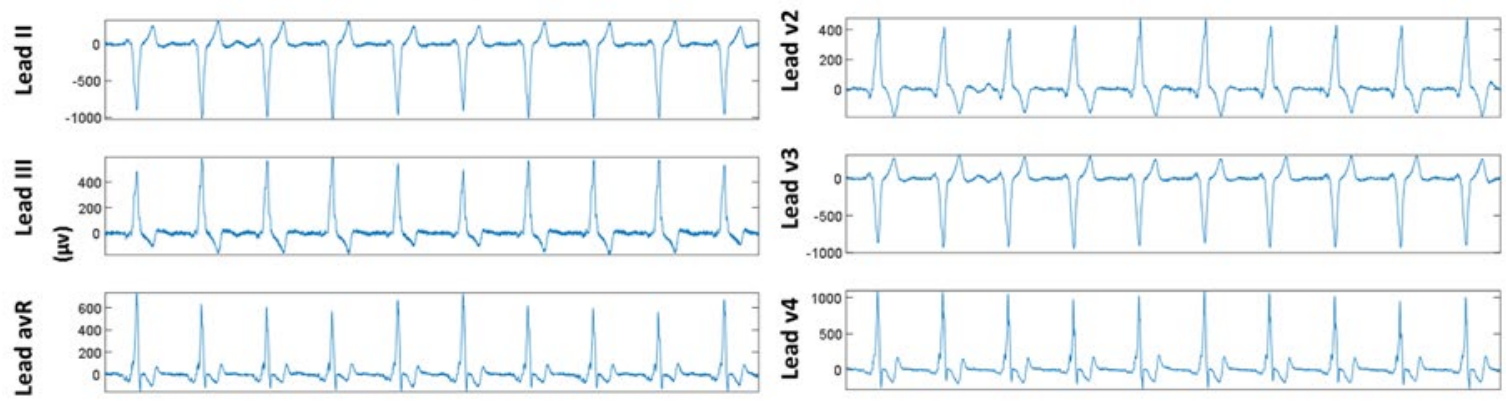

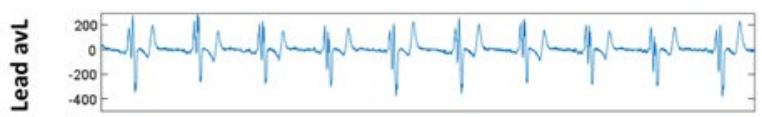

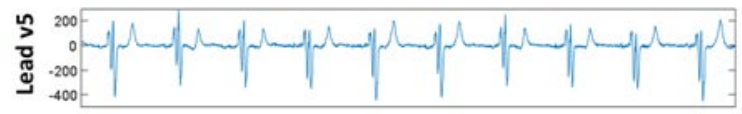

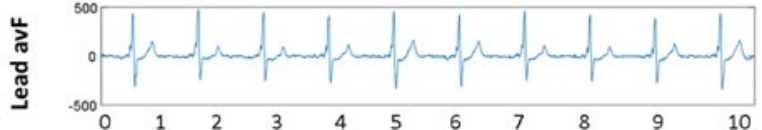

(s)

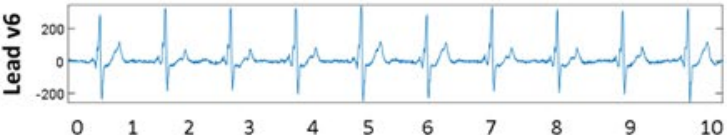

(s) 